\title{
Correction to: Early Cardiovascular Risk in E-Cigarette Users: the Potential Role of Metals
}

\author{
Ana Navas-Acien ${ }^{1} \cdot$ Irene Martinez-Morata $^{1} \cdot$ Markus Hilpert $^{1} \cdot$ Ana Rule $^{2} \cdot$ Daichi Shimbo $^{3} \cdot$ Nancy J. Lolacono $^{1}$
}

Accepted: 10 December 2020 / Published online: 16 December 2020

(C) Springer Nature Switzerland AG 2020

\section{Correction to: Current Environmental Health Reports (2020)} https://doi.org/10.1007/s40572-020-00297-y

Following the publication of the original article, the first author would like to add a correction to the published version of the article. The description of reference [55] should be changed to:

This population-based study from the Population Assessment of Tobacco and Health Wave 1 survey found that e-cigarette use is associated with a higher risk of myocardial infarction. A limitation of the study is that there are few participants who solely used e-cigarettes in the absence of past or current traditional smoking. This manuscript has been retracted but understanding the limitations of the study remains relevant.

The original article has been corrected.

Publisher's Note Springer Nature remains neutral with regard to jurisdictional claims in published maps and institutional affiliations.

The online version of the original article can be found at https://doi.org/ 10.1007/s40572-020-00297-y

Nancy J. LoIacono

nj12@cumc.columbia.edu

Ana Navas-Acien

an2737@cumc.columbia.edu

Irene Martinez-Morata

im2557@cumc.columbia.edu

Markus Hilpert

mh3632@cumc.columbia.edu

Ana Rule

arule@jhu.edu
Daichi Shimbo

ds2231@cumc.columbia.edu

1 Department of Environmental Health Sciences, Columbia University Mailman School of Public Health, 722 W 168th Street, New York, NY 10032, USA

2 Department of Environmental Health and Engineering, Johns Hopkins University, Baltimore, MD, USA

3 Department of Medicine, Columbia University Irving Medical Center, New York, NY, USA 